\title{
Down-Regulation of Connexin 32 Gene Expression through DNA Methylation in a Human Renal Cell Carcinoma Cell
}

\author{
Ayako Hirai $^{a}$ Tomohiro Yano $^{b}$ Kazuhiro Nishikawa ${ }^{a}$ Kazuyuki Suzukia \\ Ryuji Asano a Haruna Satoh ${ }^{b}$ Kiyokazu Hagiwara ${ }^{b}$ Hiroshi Yamasakic \\ aDepartment of Veterinary Pharmacology, College of Bioresource Sciences, Nihon University, Kanagawa; \\ ${ }^{b}$ Department of Food Science Research for Health, National Institute of Health and Nutrition, Tokyo, and \\ cKwansei Gaskuin University School of Science and Technology, Hyogo, Japan
}

\section{Key Words}

Connexin 32 gene $\cdot$ Renal cell carcinoma cell .

DNA methylation

\begin{abstract}
Background: We have recently reported that connexin (Cx) 32 is down-regulated in a human renal cell carcinoma (RCC) cell (Caki-2 cell). Hypothesis: We postulated that the down-regulation of $\mathrm{C} \times 32$ gene in the RCC cell is due to hypermethylation of its promoter region. Methods: We estimated methylation status in the promoter region of $\mathrm{C} \times 32$ gene in the $\mathrm{RCC}$ cell by DNA digestion with methylation-sensitive restriction enzyme and PCR, and methylation-specific PCR (MSP). We also checked the recovery of $\mathrm{Cx} 32$ gene expression in the $\mathrm{RCC}$ cell treated with a DNA methyltranferase inhibitor, 5-Aza-2'deoxycytidine (5-Aza-CdR). Results: Treatment with 5Aza-CdR resulted in induction of $\mathrm{Cx} 32$ expression in the $\mathrm{RCC}$ cell. Hypermethylation of the $\mathrm{Cx} 32$ promoter region in the RCC cell was confirmed by DNA digestion with methylation-sensitive restriction enzyme and PCR, and MSP. Conclusion: We suggest that hypermethylation in the promoter region is a mechanism for the Cx32 gene repression in the $\mathrm{RCC}$ cell.
\end{abstract}

Copyright $(2003$ S. Karger AG, Base

\section{Introduction}

Gap junctional intercellular communication (GJIC) has been considered the only route allowing direct transfer of small metabolites between cells to maintain homeostasis in multicellular organisms [1,2]. The gap junction is made up of juxtaposed transmembrane hemichannels (connexons) provided by adjacent cells, and each connexon consists of six connexin $(\mathrm{Cx})$ protein subunits [3]. So far, cDNAs from at least 15 different $\mathrm{Cx}$ molecular species have been cloned in mammals [4]. Different combinations of $\mathrm{Cx}$ molecular species in different tissues contribute to cell differentiation and cell growth control [5].

Several lines of evidence support the hypothesis that $\mathrm{Cx}$ gene acts as a tumor suppressor gene. For instance, when introduced into a human mammary carcinoma cell line, Cx26 gene conferred a reduced growth rate in cell culture, reduced tumor growth and restoration of differentiation potential in nude mice [6]. Recent studies including our reports have suggested that not all $\mathrm{Cx}$ molecular species are able to exert a tumor-suppressive effect on a given tumor, but rather than that there seems to be a Cx-cell type compatibility for this effect [7-10]. That is, Cx exerts growth control only in tissues or cell types in which the particular $\mathrm{Cx}$ is naturally expressed. In a recent report, we have shown that $\mathrm{Cx} 32$ mainly ex-

\begin{tabular}{ll}
\hline KARGER & ( ) 2003 S. Karger AG, Basel \\
0250-8095/03/0233-0172\$19.50/0 \\
$\begin{array}{l}\text { Fax +4161306 1234 } \\
\begin{array}{l}\text { E-Mail karger@karger.ch } \\
\text { www.karger.com }\end{array}\end{array}$ & $\begin{array}{l}\text { Accessible online at: } \\
\text { www.karger.com/ajn }\end{array}$
\end{tabular}

Tomohiro Yano, $\mathrm{PhD}$

Department of Food Science Research for Health

National Institute of Health and Nutrition

1-23-1 Toyama, Shinjuku-ku, Tokyo162-8636 (Japan)

Tel. +8133203 8063, Fax +81 33205 6549, E-Mail yano@nih.go.jp 
presses in normal human renal epithelial cell (a main progenitor cell of RCC), while the down-regulation of $\mathrm{Cx} 32$ occurs in a human RCC cell line, Caki-2 cell [11]. Also, we have confirmed that the same event occurs in human kidney tissue [11]. From the report, $\mathrm{Cx} 32$ may act as a tumor suppressor gene against the RCC cell. The mechanism underlying the repression of $\mathrm{Cx} 32$ in the RCC cell remains to be defined.

Of silencing mechanisms on tumor suppressor genes, aberrant promoter region methylation of $\mathrm{CpG}$ islands has attracted a great deal of attention as a mechanism of transcriptional inactivation. Aberrant cytosine methylation at $\mathrm{CpG}$ in the $5^{\prime} \mathrm{CpG}$ islands has been associated with repression of transcription, and it is an important and common mechanism for silencing of tumor suppressor genes [12]. In this context, the present study was carried out to estimate if hypermethylation of DNA was responsible for the repression of $\mathrm{Cx} 32$ expression in the Caki-2 cell.

\section{Methods}

\section{Cell Lines}

HK-2, a SV-40-immortalized human renal tubular cell line and a human renal carcinoma cell line Caki-2, were obtained from American Type Culture Collection (ATCC), and maintained in media and culture conditions as described in the following: both cell lines were cultured in McCoy's 5A medium (Invitrogen, Calif., USA) supplemented with $10 \%$ fetal bovine serum (FBS) and penicillin-streptomycin sulfate on standard plastic tissue culture dishes and incubated in an atmosphere of $95 \% \mathrm{air} / 5 \% \mathrm{CO}_{2}$ at $37^{\circ} \mathrm{C}$.

\section{$R T-P C R$}

Total cellular RNA of each cell line was isolated using SV Total RNA Isolation System (Promega, Wisc., USA) as described in the manufacturer's manual, and cDNA was synthesized using Superscript Reverse Transcriptase (Invitrogen). Amplification of the Cx32 gene was performed using synthetic oligonucleotides (sense primer, 5'-ATGAACTGGACAGGTTTGTAC-3'; antisense primer, 5'-ATGTGTTGCTGGTGAGCCA-3'; PCR product, 301 bp). GAPDH (sense primer, 5'-GTATGTGGAAGGACTCATG-3'; antisense primer, 5'-GTTTTTCTAGACGGCACCTCA-3'; PCR product, $249 \mathrm{bp}$ ) was used for an internal control. The condition for amplification was carried out by an initial denaturation at $94^{\circ} \mathrm{C}$ for $2 \mathrm{~min} ; 35$ cycles of $94^{\circ} \mathrm{C}$ for $30 \mathrm{~s}, 56^{\circ} \mathrm{C}$ for $1 \mathrm{~min}, 72^{\circ} \mathrm{C}$ for $1 \mathrm{~min}$, and a final extension for $5 \mathrm{~min}$ at $72^{\circ} \mathrm{C}$. The PCR products were electrophoresed on $1.5 \%$ agarose gels, and stained with GelStar Nucleic Acid Gel Stain (Takara, Japan). Wide-Range DNA Ladder (Takara) was used as markers for sizing the RT-PCR products.

\section{5-Aza-2'-Deoxycytidine (5-Aza-CdR) Treatment}

Caki-2 cells were treated with 5 -Aza-CdR. $5 \times 10^{5}$ cells were seeded on a $60-\mathrm{mm}$ plate and incubated for $24 \mathrm{~h}$. The cells were cultured up to 14 days in complete media which contained various concentrations of 5-Aza-CdR $(2.5,5$ and $10 \mu M)$, and media was changed at 3-day intervals. After that total cellular RNA was isolated to analyze $\mathrm{Cx} 32$ expression with RT-PCR. In order to estimate the level of $\mathrm{C} \times 32$ mRNA semiquantitatively, the ratio of $\mathrm{C} \times 32$ to GAPDH in mRNA level was calculated by densitometric analysis using Atto Image Analysis Software (Atto, Japan).

\section{Methylation-Sensitive Restriction Enzymes and PCR}

Methylation status of promoter region was determined by digestion with methylation-sensitive restriction enzyme, followed by a PCR method [13]. Genomic DNAs from each cell lines (HK2 and Caki-2) are digested with MspI and HpaII (Roche Diagnostics, Germany) restriction enzymes. Reaction, either no enzyme, or 75 units of $\mathrm{HpaII}$, or 150 units of $M s p \mathrm{I}$ was carried out at $37^{\circ} \mathrm{C}$ overnight. To determine the fragment of promoter region, $2 \mu \mathrm{l}$ of each samples amplified by PCR in $25-\mu 1$ reactions containing $10 \mathrm{~m} M$ Tris- $\mathrm{HCl}$ (pH 8.3), $50 \mathrm{~m} M \mathrm{KCl}, 1.5 \mathrm{~m} M \mathrm{MgCl}_{2}, 100 \mu M$ dNTP, 0.5 units of Taq polymerase (Takara), and $50 \mathrm{ng}$ of each primer (sense primer, 5'-GCTCTCTTTCCTGTCCTCTTT-3'; antisense primer 5'-AGCCCATCTTGTTCCGATA-3'; PCR product, 623 bp). PCR was performed with at first an initial denaturation at $94^{\circ} \mathrm{C} 4 \mathrm{~min}$, followed with 35 cycles of $94^{\circ} \mathrm{C}$ for $1 \mathrm{~min}, 56^{\circ} \mathrm{C}$ for $1 \mathrm{~min}$, and $72^{\circ} \mathrm{C}$ for $2 \mathrm{~min}$, and a final extension for $72^{\circ} \mathrm{C}$ for $7 \mathrm{~min}$. PCR products were analyzed as described previously. PCR products will be found at the promoter having methylated status when digested with HpaII. No products will be found at the promoter having unmethylated status when digested with HpaII. All of the samples digested with MspI will have no products.

\section{Methylation Specific-PCR (MSP)}

The chemical modification of cytosine to uracil by bisulfite treatment is another method for study of DNA methylation. In this reaction, all cytosines are converted to uracil but 5 -methylcytosines are resistant to the modification and remain as cytosine. For extraction of genomic DNA from cell lines we used Gen Elute Mammalian Genomic DNA kit (SIGMA, Japan) as per manufacturer's protocol. Bisulfite reaction was carried out on genomic DNA as described in the following [14]; the bisulfite conversion reaction was carried out by incubating DNA with a $5 M$ bisulfite solution and $100 \mathrm{~m} M$ hydroquinone, $\mathrm{pH} 5.0$, at $50^{\circ} \mathrm{C}$ for $4 \mathrm{~h}$. Removal of surplus bisulfite was attained by using QIAEX II Gel Extraction Kit (Qiagen, Japan). Initially, bisulfite-treated genomic DNA was amplified using methylated-specific primers for $\mathrm{Cx} 32$ (Cx32M); sense primer, 5'-GGGGCGGGTGCGGCGAT-3' and antisense primer, 5'-CTCCGCGCCT $\underline{G}-$ CGCCC-3', and unmethylated-specific primers for $\mathrm{Cx} 32$ (Cx32UM); sense primer, 5'-GGGGTGGGTGTGGTGAT-3' and antisense primer, 5'-CTCCACACCTACACCCAA- ${ }^{\prime}$ ). The PCR product was $245 \mathrm{bp}$ and differences between methylated and unmethylated were underlined. KOD-Plus DNA polymerase (Toyobo, Japan) was used in this PCR reaction to effectively amplify $\mathrm{CpG}$ island regions. The $\mathrm{PCR}$ condition was carried out by an initial denaturation at $94^{\circ} \mathrm{C}$ for $2 \mathrm{~min} ; 40$ cycles of $94^{\circ} \mathrm{C}$ for $30 \mathrm{~s}, 68^{\circ} \mathrm{C}$ for 1 min according to manufacturer's manual.

\section{Immunoblotting Analysis}

As described previously, $20 \mu \mathrm{g}$ of total protein extract from each clone was loaded onto a $10 \%$ gel for $\mathrm{Cx} 32$ and $\beta$-actin. $\beta$-Actin was used as an internal standard. After electrophoresis, proteins were transferred to nitrocellulose membranes. The blots were incubated with anti-Cx32 and anti- $\beta$-actin antibodies (Sigma). Each immunoreactive band was detected using the ECL system (Amersham, UK) 
and a cooled CCD camera-linked Cool Saver system (Atto). A 2-D densimetric evaluation of each band was performed using the above Image Analysis Software (Atto). Molecular sizing was done using Rainbow MW marker (Amersham). Protein concentrations were determined using DC Protein Assay System (BioRad, USA).

\section{Scrape-Loading Analysis on Cell-Cell Communication}

The degree of cell-cell communications was measured by the extent of Lucifer yellow dye transfer from cells to cells through the gap junctions by a simple semiquantitative scrape-loading method [15]. In brief, $0.05 \%$ Lucifer yellow and rhodamine dextran dissolved in PBS were added to the cells and scrape-loaded at room temperature using a rubber policeman. The dye solution was left on the cells for $3 \mathrm{~min}$, discarded and the plate was rinsed with PBS. Control plates were set by exposing the cells under similar conditions to the dye mixture but without scraping. Under fluorescent microscopic examination, the loading cells could pick up the dye mixture and were able to transfer Lucifer yellow into the neighboring cells through functional gap junctions. On the other hand, the marker dye rhodamine dextran remained entrapped, thus labeling the primary loaded at the edge of the scraped areas.

\section{Statistical Analysis}

Data were analyzed by one-way ANOVA followed by Duncan's multiple-range test. $p$ values of 0.05 or less were considered significant.

\section{Results}

\section{Effect of 5-Aza-CdR on Cx32 Expression in Caki-2}

Cells

5-Aza-CdR is an inhibitor of DNA methyltransferase, the enzyme responsible for maintaining DNA methylation patterns in newly synthesized DNA [16]. Treatment of cells with 5-Aza-CdR leads to expression reversion of the gene which is inactivated by promoter methylation. Using 5-Aza-CdR, we estimated if the re-expression of Cx32 occurred in Caki-2 cells. As shown in figure 1a, 5Aza-CdR treatment caused the induction of $\mathrm{Cx} 32 \mathrm{mRNA}$ in the cells, and the expression level of $\mathrm{Cx} 32 \mathrm{mRNA}$ expressed as the $\mathrm{Cx} 32 / \mathrm{GAPDH}$ ratio increased in a dose dependent manner (the value, control, $0 \%$; 5-Az-CdR $(2.5 \mu M), 50.2 \%$; 5-Az-CdR $(5 \mu M), 85.5 \%$; 5-Az-CdR $(10 \mu M), 100 \%)$. As well, the level of Cx32 protein in Caki-2 cells was significantly elevated by the treatment of $10 \mu M$ 5-Az-CdR, while the level in HK-2 cells (a progenitor cell of human RCC cell) was almost unchanged (fig. 1b, c). In conjugation with this event, the treatment significantly increased cell-cell communication in Caki-2 cells; on the contrary, the treatment did not affect the communication in HK-2 cells (fig. 1d). These results suggest that the silencing of $\mathrm{Cx} 32$ gene and deficiency in cellcell communication in Caki-2 cells relates to DNA methylation.

\section{Methylation Status in the Promoter Region of the Cx32 Gene}

In order to further clarify hypermethylation of the $\mathrm{Cx} 32$ gene promoter region, we used the methylation-sensitive restriction enzyme/PCR [13] and the MSP methods [14]. In the restriction enzyme/PCR analysis, we estimated methylation status of a region containing exon 1 and an upstream promoter region of $\mathrm{Cx} 32$ with TATA box in the middle, because the entire region is an extremely GC-rich $\mathrm{CpG}$ island $(\mathrm{G}+\mathrm{C}$ content; above $60 \%)$. Furthermore, the exon 1, which has no translation of the $\mathrm{Cx} 32$ transcription, is extremely GC-rich and contains the normally underrepresented $\mathrm{CpG}$ dinucleotide at the expected frequency, indicating that the exon 1 contributes to transcriptional regulation of $\mathrm{Cx} 32$. Then, we included the exon 1 in this analysis. A 623bp DNA fragment is successfully amplified from intact DNA samples which were resulted from no digestion control or methylated DNA resisting the digestion by $H p a I I$, a methylation sensitive enzyme. Since the analyzed promoter site contains four HpaII recognition sites, no PCR products are found in unmethylated DNA samples digested with HpaII. Also, all samples treated with $M s p$ I show no PCR products. As shown in figure $2 \mathrm{a}$, the PCR product was observed in no digestion samples of HK-2 and Caki-2 cells. Caki-2 cells, which had no detectable Cx32 mRNA, were resistant to digestion by $H p a \mathrm{II}$ and sensitive to digestion $M s p \mathrm{I}$, while HK-2 cells, which expressed Cx32, were sensitive to digestion by HpaII and MspI (fig. 2b). These results suggest that the silencing of $\mathrm{Cx} 32$ gene expression in Caki-2 cells correlates with hypermethylation of the gene promoter region.

In MSP, genomic DNA is treated with bisulfite under conditions that convert cytosine to uracil but that do not affect 5-methyluracil, and then PCR amplification of the modified DNA is carried out with a set of primers designed to distinguish methylated and unmethylated alleles in bisulfite-modified DNA [14]. The primer sequences for $\mathrm{Cx} 32$ were chosen for the above promoter region of $\mathrm{Cx} 32$ containing $\mathrm{CpG}$ pairs. As shown in figure 2c, Caki-2 cell showed positive for the PCR using $\mathrm{Cx} 32 \mathrm{M}$ primers and negative for the PCR using Cx32UM primers. On the contrary, HK-2 cells showed the opposite result for the MSP. This MSP result further supports that the silencing of $\mathrm{Cx} 32$ gene expression in Caki-2 cells is caused by hypermethylation of the gene promoter region. 

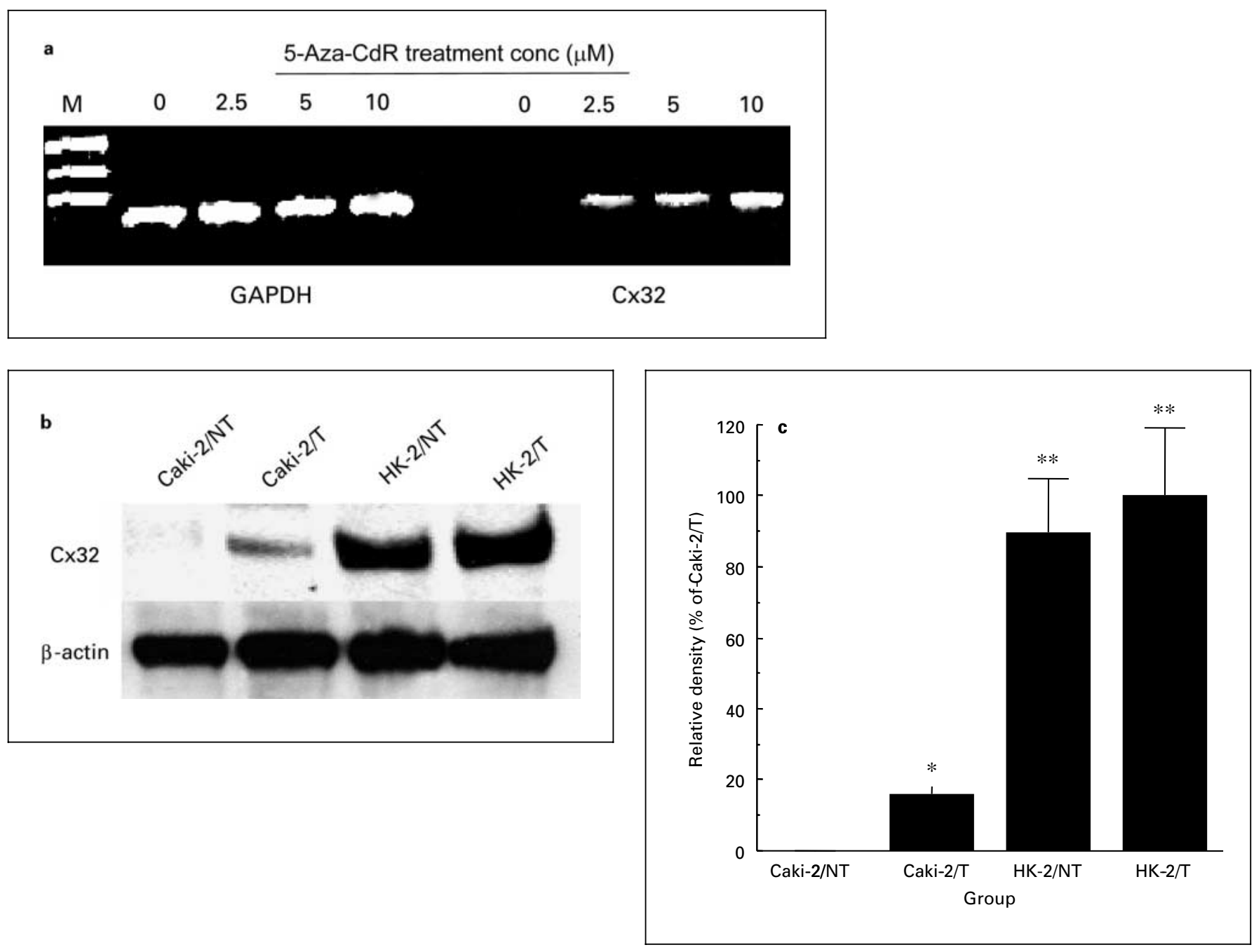

Fig. 1. $\mathrm{Cx} 32$ expression before and after treatment with 5-Aza-CdR. a Effect of increasing concentrations of 5-Aza-CdR on the levels of Cx32 mRNA in Caki-2 cells. $M=$ Molecular marker. This result is representative of one of two independent experiments. b, c Effects of 5-Aza-CdR $(10 \mu M)$ on Cx32 protein levels in Cak-2 and HK-2 cells and their densitometric evaluation. Caki-2/NT, non-treated Caki-2 cells; Caki-2T, 5-Aza-CdR-treated Caki-2 cells; HK-2/NT, nontreated HK-2 cells; HK-2/T, 5-Aza-CdR-treated HK-2 cells. This result is representative of one of three independent experiments. Each value is expressed as relative ratio against HK-2/T, and the value in HK-2/T is shown as $100 \%$. Each intensity shown is the mean of three samples and vertical lines indicate SD. ${ }^{*}$ Significant difference from Caki-2/NT. ** Significant difference from Caki-2/NT and Caki-2/T. d Effect of 5-Aza-CdR on the capability of cell-cell communication through gap junctions, measured by the number of cell layers receiving Lucifer Yellow dye transfer from the dye loading cells. Fifty loading cells were examined and the capability of Lucifer Yellow dye transfer was expressed as an average number of cells receiving the dye from the loading cell. Each column represents the mean and vertical lines indicate SD. * Significant difference from Caki-2/NT. ${ }^{* *}$ Significant difference from Caki-2/NT and Caki-2/T.

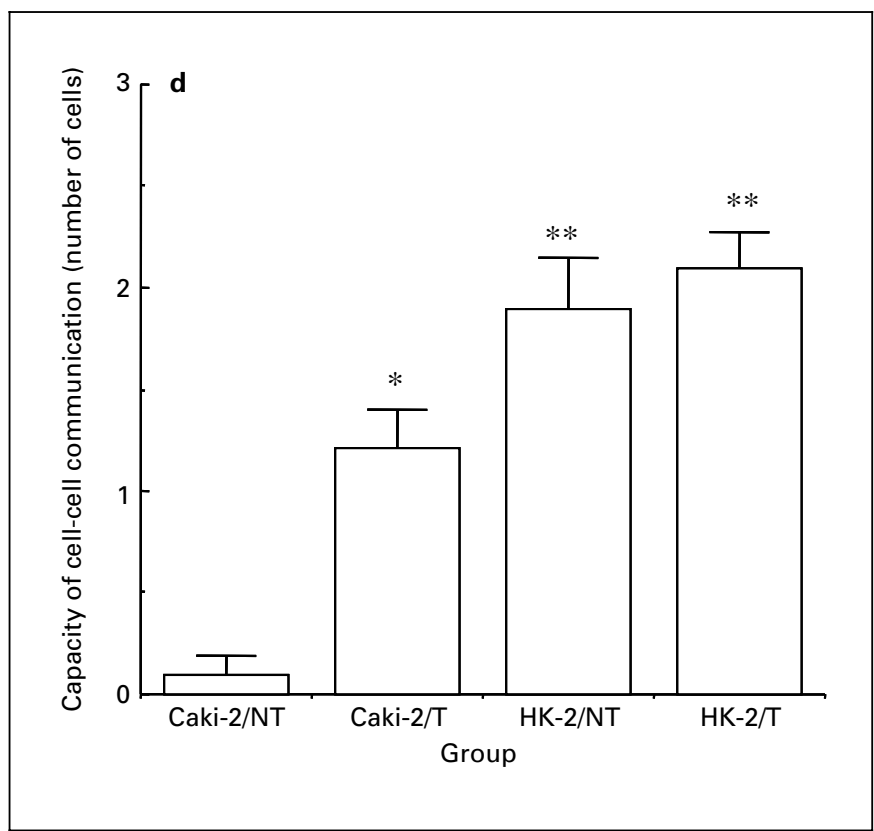

Down-Regulation of Connexin 32 in RCC 

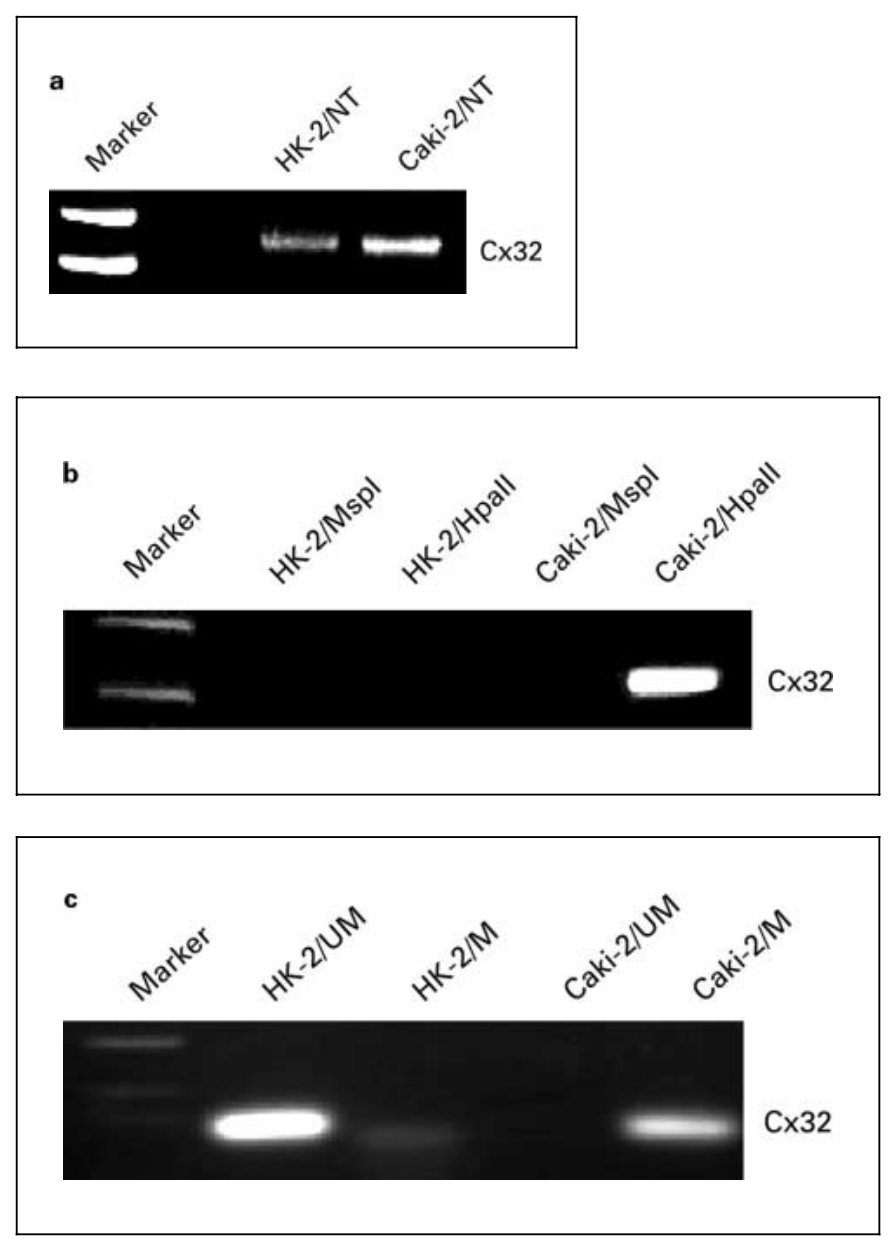

Fig. 2. Methylation status of $\mathrm{Cx} 32$ promoter region in HK-2 and Caki- 2 cells. a PCR for $\mathrm{Cx} 32$ in DNA samples from non-treated cells. HK-2/NT, non-treated HK-2 cells; Caki-2/NT, non-treated Caki-2 cells. b methylation-sensitive restriction enzyme/PCR analysis for Cx32. After MspI and HpaI restrction enzymes' digestion, PCR for Cx32 was carried out. HK-2/MspI, MspI-treated HK-2 cells; HK-2/ HpaII, HpaII-treated HK-2 cells; Caki-2/MspI, MspI-treated Caki-2 cells; Caki-2/HpaII, HpaII-treated Caki-2 cells. c Methylation-specific PCR of Cx32 in HK-2 and Caki-2 cells. The presence of the PCR product in the lanes, Caki-2/UM (Caki-2 cells) and HK-2/UM (HK-2 cells) indicate the presence of unmethylated $\mathrm{C} \times 32$ gene and the PCR product in the lanes, Caki-2/M (Caki-2 cells) and HK-2/M (HK-2 cells) indicate the presence of methylated Cx32 gene. PCR using unmethylated-specific primers for $\mathrm{Cx} 32$ was carried out in UM groups, and PCR using methylated-specific primers for $\mathrm{Cx} 32$ was carried out in M groups, as mentioned in 'Methods'. Each result is representative of one of two independent experiments.

\section{Discussion}

Since $\mathrm{Cx}$ genes have been suggested as tumor suppressor genes, it is expected that they are deleted and/or mutated in certain cancers, similar to many other known tumor suppressor genes. However, mutations in $\mathrm{Cx}$ genes including $\mathrm{Cx} 32$ were found to be rare events in carcinogenesis [17]. Thus, the question arose that how the tumor suppressor gene lost its function in carcinogenesis if there were no mutations. It is reasonable to assume that another mechanism, such as transcriptional inactivation, is important. Methylation of cytosine residues in $\mathrm{CpG}$ islands of the promoter region of genes has become recognized as an alternative mechanism for inactivation of tumor suppressor genes and may in fact be the most common mechanism of gene inactivation in tumors [18]. This hypothesis was strongly supported by recent studies showing that the $\mathrm{CpG}$ islands in p16, RB, VHL, APC and BRCA1 genes are frequently methylated in a variety of human cancers [19]. As mentioned above, it has been known that the promoter and proximal transcribed region of the $\mathrm{Cx} 32$ gene is $\mathrm{CpG}$ rich. This prompted us to examine the possibility of hypermethylation at the promotion region as a mechanism of $\mathrm{Cx} 32$ gene repression in Caki- 2 cells. In our present study, we demonstrated that hypermethylation of the $\mathrm{C} \times 32$ promoter region and silencing of the $\mathrm{C} \times 32$ gene occurred in Caki-2 cells. Furthermore, 5-Az-CdR treatment induced the re-expression of Cx32 mRNA and recovery of capacity of cell-cell communication in Caki-2 cells. However, the recovery levels in Caki-2 cells were significantly lower than the levels in HK-2 cells. This indicates that the hypermethylation of the promoter region in $\mathrm{Cx} 32$ gene is a factor to induce the repression of the gene but that 5-Az-CdR-dependent release of the hypermethylation is insufficient to bring $\mathrm{Cx} 32$ expression and the capacity of cell-cell communication in Caki- 2 cells back to that in immortalized renal epithelial cells. 5-Az-CdR has cellular toxicities even if the treatment dose is relatively low, so the toxicity may interfere with the complete recovery of $\mathrm{Cx} 32$ expression and the communication capacity in Caki-2 cells.

We have already reported that silencing of the $\mathrm{C} \times 32$ gene frequently occurs in human RCC tissues [17]. From the report and our present data, it seems possible that the silencing of $\mathrm{Cx} 32$ gene mainly depends on the hypermethylation of the promoter region in human RCC tissues as well as Caki-2 cells. In order to confirm this possibility, we are trying to estimate if the hypermethylation of the promoter region in $\mathrm{Cx} 32$ gene relates to the silencing of the gene in human RCC tissues. We have demonstrated

\footnotetext{
$\overline{176} \quad \overline{\text { Am J Nephrol 2003;23:172-177 }}$
} 
that the recovery of $\mathrm{Cx} 32$ gene expression in Caki- 2 cells reduces their malignant phenotypes such as anchorage independence [17]. Thus, if we confirm that the hypermethylation-mediated down-regulation of the $\mathrm{Cx} 32$ gene is generally observed in human RCC tissues, attenuating the silencing of $\mathrm{Cx} 32$ gene via hypermethylation of its promoter region leads to establishment of a new preventive procedure against the RCC.

\section{Acknowledgement}

This study was supported by a research grant from the Japan Health Sciences Foundation (grant SH24209).

\section{References}

1 Mesnil M, Yamasaki H: Cell-cell communication and growth control of normal and cancer cells: Evidence and hypothesis. Mol Carcinogenesis 1993; 7:14-17.

2 Saez JC, Connor JA, Spray DC, Bennett MVL: Hepatocyte gap junctions are permeable to the second messenger, inositol 1,4,5-triphosphate and calcium ions. Proc Natl Acad Sci USA 1989;86:2708-2712.

3 Stauffer KA, Kumar NM, Gilula NB, Unwin $\mathrm{N}$ : Isolation and purification of gap junction channels. J Cell Biol 1991;115:141-150.

4 Bruzzone R, White TW, Paul DL: Connections with connexins: The molecular basis of direct signaling. Eur J Biochem 1996;238:1-27.

5 Kumar NM, Gilula NB: The gap junction communication channel. Cell 1996;84:381-386.

6 Rose B, Mehta PP, Loewenstein WR: Gapjunction protein gene suppresses tumorigenicity. Carcinogenesis 1996;14:1073-1075.

7 Yano T, Francisco-Javier HB, Omori Y, Yamasaki $\mathrm{H}$ : Reduction of maliganant phenotype of HepG2 cell is associated with the expression of connexin 26 but not connexin 32. Carcinogenesis 2001;22:1593-1600.
8 Yano T, Yamasaki H: Regulation of cellular invasion and matrix metallo-proteinase activity in HepG2 cell by connexin 26 transfection. Mol Carcinogenesis 2001;31:101-109.

9 Mesnil M, Kruovskikh C, Piccoli C, Elfgang C, Traub O, Willecke K, Yamasaki H: Negative growth control of HeLa cells by connexin genes: Connexin species specificity. Cancer Res 1995:55:629-639.

10 Zhu D, Caveney S, Kidder GM, Naus CCG: Growth retardation in glioma cells overexpressing a gap junction protein. Proc Natl Acad Sci USA 1991;88:1883-1887.

11 Yano T, Iot F, Satoh H, Hagiwara K, Nakazawa $\mathrm{H}$, Toma $\mathrm{H}$, Yamasaki H: Tumor-suppressive effect of connexin 32 in renal cell carcinoma. Kidney Int 2003; in press.

12 Jones PA, Laird PW: Cancer epigenetics comes of age. Nature Genet 1999;21:163-167.

13 Singer-Sam J, Grant M, LeBon JM, Okuyama K, Chapman V, Monk M, Riggs AD: Use of a HpaII-polymerase chain reaction assay to study DNA methylation in the Pgk-1 CpG island of mouse embryos at the time of X-chromosome inactivation. Mol Cell Biol 1990;10: 4987-4989.
14 Herman JG, Graff JR, Myohanen S, Nelkin BD, Baylin SB, Methylation- specific PCR: A novel PCR assay for methylation status of $\mathrm{CpG}$ islands. Proc Natl Acad Sci USA 1996;93: 9821-9826.

15 El-Fouly MH, Trosko JE, Chang CC: Scrapeloading and dye transfer: A rapid and simple technique to study gap junctional intercellular communication. Exp Cell Res 1987;168:422430.

16 Frieman S: The irreversible binding of azacytosine-containing DNA fragments to bacterial DNA (cytosine-5) methyltransferases. J Biol Chem 1985;260:5698-5705.

17 Omori Y, Krutovskikh V, Mironov N, Tsuda $\mathrm{H}$, Yamasaki $\mathrm{H}$ : $\mathrm{Cx} 32$ gene mutation in a chemically induced rat liver tumour. Carcinogenesis 1996;17:2077-2080.

18 Baylin SB, Herman JG, Graff JR, Vertino PM, Issa JP: Alterations in DNA methylation: A fundamental aspect of neoplasia. Adv Cancer Res 1998;72:141-196.

19 Herman JG, Baylin SB: Promoter-region hypermethylation and gene silencing in human cancer. Curr Top Microbiol Immunol 2000; 249:35-54. 